\title{
Metastatic sebaceous cell carcinoma, review of the literature and use of electrochemotherapy as possible new treatment modality
}

\author{
Simone Ribero ${ }^{1,2}$, Eugenio Sportoletti Baduel ${ }^{1,2}$, Matteo Brizio ${ }^{1}$, Franco Picciotto², \\ Emi Dika ${ }^{3}$, Maria Teresa Fierro1, Giuseppe Macripò ${ }^{2}$, Pietro Quaglino ${ }^{1}$ \\ 1 University of Turin, Department of Medical Sciences, Section of Dermatology, Turin, Italy \\ ${ }^{2}$ Città della Salute e della Scienza di Torino University Hospital, Department of Oncology, Section of Dermatologic Surgery, \\ Turin, Italy \\ ${ }^{3}$ Unit of Dermatology, Department of Experimental, Diagnostic and Specialty Medicine, University of Bologna, Bologna, Italy
}

Radiol Oncol 2016; 50(3): 308-312.

Received 24 April 2016

Accepted 14 May 2016

Correspondence to: Simone Ribero, M.D., Ph.D., Department of Medical Sciences, Section of Dermatology, University of Turin, Turin, Italy. E-mail: simone.ribero@unito.it

Disclosure: No potential conflicts of interest were disclosed.

\begin{abstract}
Background. Metastatic extraorbital sebaceous carcinoma is a rare event that could involve the head and neck. The treatment of choice for the initial stage of the disease is surgery and/or radiotherapy. The treatment of recurrent or advanced disease is still controversial.

Material and methods. Extensive literature search was done, and the treatment options are discussed.

Results. Results. The literature search found several treatment modalities in use for the treatment of metastatic extraorbital sebaceous carcinoma. Electrochemotherapy was not included in the reported treatments. We used this technique for a man of 85 years old with a recurrent and locally metastatic extraorbital sebaceous carcinoma of the scalp.During the period of 8 months, two sessions of electrochemotherapy were employed, which resulted in an objective response of the tumour and good quality of life.

Conclusions. Electrochemotherapy has shown to be a interesting tools for treatment of metastatic extraorbital sebaceous carcinoma when other radical options are not available or convenient.
\end{abstract}

Key words: electrochemotherapy; head and neck tumour; extraorbital tumour; sebaceous carcinoma

\section{Introduction}

The sebaceous carcinoma (SC) is a rare and potentially aggressive adnexial neoplasm of sebaceous gland. Its prevalence varies from $0.05 \%$ to $0.7 \%$ of all the skin cancers. ${ }^{1}$ Approximately, the $25 \%$ of sebaceous carcinomas occur in extra-orbital sites, in $15 \%$ of these cases the torso and in $10 \%$ the extremities are affected. ${ }^{2}$

Extraorbital SC is considered as a less aggressive neoplasm when compared with its periorbital counterpart (a reduced tendency for regional metastasis, $1.4 \%$ for extraorbital vs. $4.4 \%$ for periorbital). ${ }^{3}$ Despite this, highly aggressive extraorbital SC has been reported in the literature. ${ }^{4}$
The typical clinical presentation is indistinguishable from other more common dermatologic conditions. Usually, clinical features are a painless pink or yellow firm papule, gradually enlarging and ranging from skin-coloured to red papules, plaques, or nodules. This aspecific presentation delays the time of diagnosis. Histologically an unencapsulated, lobular, dermally based collections of sebaceous and undifferentiated cells that may contain lipid granules in the cytoplasm with a characteristic "frothy" appearance. ${ }^{5}$

SC requires vigilant follow-up after treatment due to its potentially aggressive nature. Local recurrence rate is $4 \%-28 \%$ for both periorbital and extraorbital lesions. ${ }^{6}$ 
Pathogenesis of SC is poorly understood, however associations with Muir-Torre syndrome ${ }^{7}$ is described as well as irradiation ${ }^{8}$, immunosuppression ${ }^{9}$, familial retinoblastoma. ${ }^{10}$ This neoplasm can occur on any sebaceous glands rich skin, particularly face, scalp, and neck. For unknown reasons SC is more prevalent in periorbital skin (39\%), especially eyelid, and in extraorbital skin of the head and neck (41\%). Some genitalis and extremities cases are reported. ${ }^{11}$

The management of skin cancer of the head and neck region is still challenging. Surgery is commonly considered the treatment of choice and significantly improves the locoregional control, if associated with adjuvant radiotherapy. ${ }^{12}$ In the head and neck area, where it is difficult to obtain safety margins wide enough, radiotherapy can be the first treatment option. In particular some areas have been included in the last American Joint Committee on Cancer (AJCC) classification as more at risk of involved margins after surgery in squamous cell carcinoma. ${ }^{13}$

\section{Methods}

A systematic literature review for case reports of extra-ocular, cutaneous, multifocal metastasizing SC in the time between 1960 and 2015 was conducted. We therefore searched the literature for all cases mentioning a skin directed therapy and response results for metastatic sebaceous carcinoma utilizing PubMed's MEDLINE database.
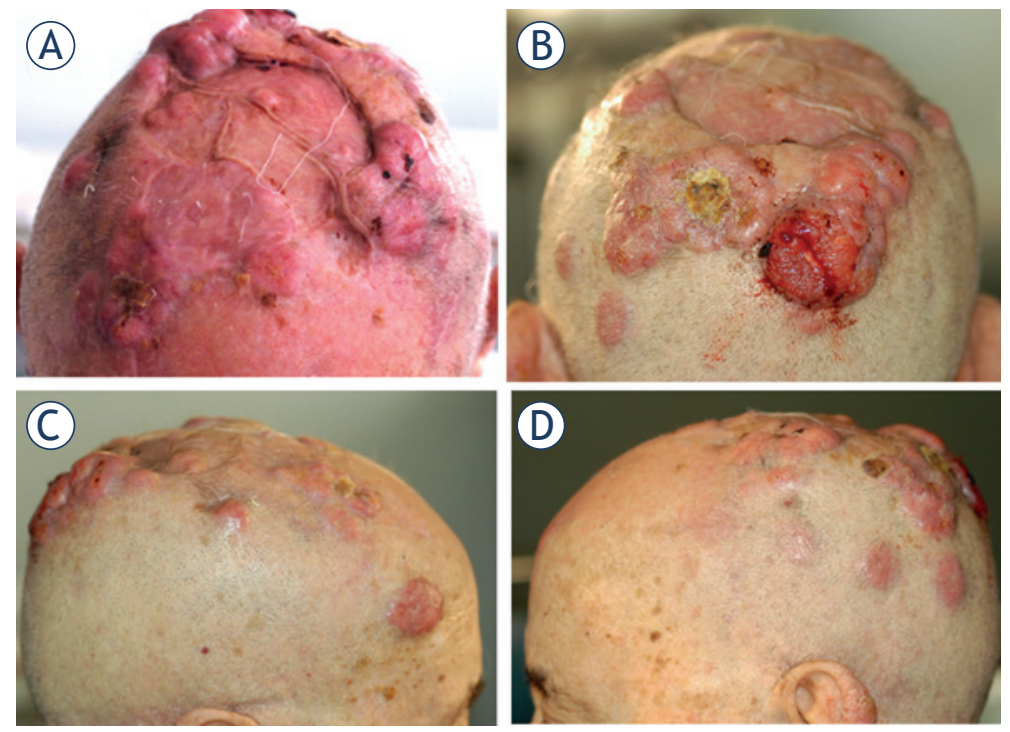

FIGURE 1. Metastatic sebaceous carcinoma, before electrochemotherapy.

\section{Results}

Local and distant cutaneous/subcutaneous metastases were described in the course of disease in 8 cases (Table 1).$^{14-21}$ Heterogeneity regarding managing of skin cutaneous metastases in head and neck is due to the variability in size, site and clinical comorbidities. Although a few reported cases have shown that skin directed therapy regimens help in palliative treatment, prospective studies have not been performed and their role has not yet been settled due to the rarity of this disease.

TABLE 1. Clinical cases of extra-ocular metastatic sebaceous carcinoma treated with skin directed therapies

\begin{tabular}{|c|c|c|c|c|c|}
\hline Authors & Sex & Age & Localization / metastases & Treatment & Prognosis \\
\hline Mellette et al. (1981) ${ }^{14}$ & M & 63 & Nose / cutaneous and paratiroid metastases & $\begin{array}{c}\text { Curettage and surgical excision } \\
\text { Parotidectomy } \\
\text { Radiotherapy }\end{array}$ & nod \\
\hline Moreno et al. (2001) 16 & M & 45 & Left axilla / lymph node metastases & Surgery & 6 months \\
\hline Moura et al. (2002) ${ }^{17}$ & M & 71 & $\begin{array}{l}\text { Forehead / cutaneous, nodal and skeletal } \\
\text { metastases }\end{array}$ & $\begin{array}{c}\text { Surgery } \\
\text { Local radiation } \\
\text { Chemo and cryosurgery }\end{array}$ & $\begin{array}{l}4 \text { years without } \\
\text { recurrence }\end{array}$ \\
\hline Khan et al. (2003) ${ }^{18}$ & $\mathrm{~F}$ & 49 & Vulva / subcutaneous and nodal metastases & $\begin{array}{c}\text { Surgery } \\
\text { Radiotherapy } \\
\text { Palliative chemotherapy }\end{array}$ & nod \\
\hline Murphy et al. (2004) 19 & M & 71 & Right nostril / left nostril metastases & Surgery & $\begin{array}{l}18 \text { months without } \\
\text { recurrence }\end{array}$ \\
\hline Swick et al. (2009) 20 & M & 83 & $\begin{array}{l}\text { Right flank / subcutaneous, nodal, } \\
\text { pulmonary and hepatic metastases }\end{array}$ & Palliative radiotherapy & nod \\
\hline Bhat et al. $(2011)^{21}$ & M & 32 & Left feet / cutaneous metastases & $\begin{array}{l}\text { Surgery } \\
\text { Chemotherapy }\end{array}$ & nod \\
\hline Bolm et al. (2015) ${ }^{15}$ & M & 87 & $\begin{array}{l}\text { Left ear / nodal, pulmonary and cutaneous } \\
\text { metastases }\end{array}$ & Surgery & $\begin{array}{l}18 \text { months without } \\
\text { recurrence }\end{array}$ \\
\hline Our case & M & 85 & $\begin{array}{c}\text { Scalp / cutaneous and subcutaneous } \\
\text { metastases }\end{array}$ & Electrochemotherapy & 2 months \\
\hline
\end{tabular}



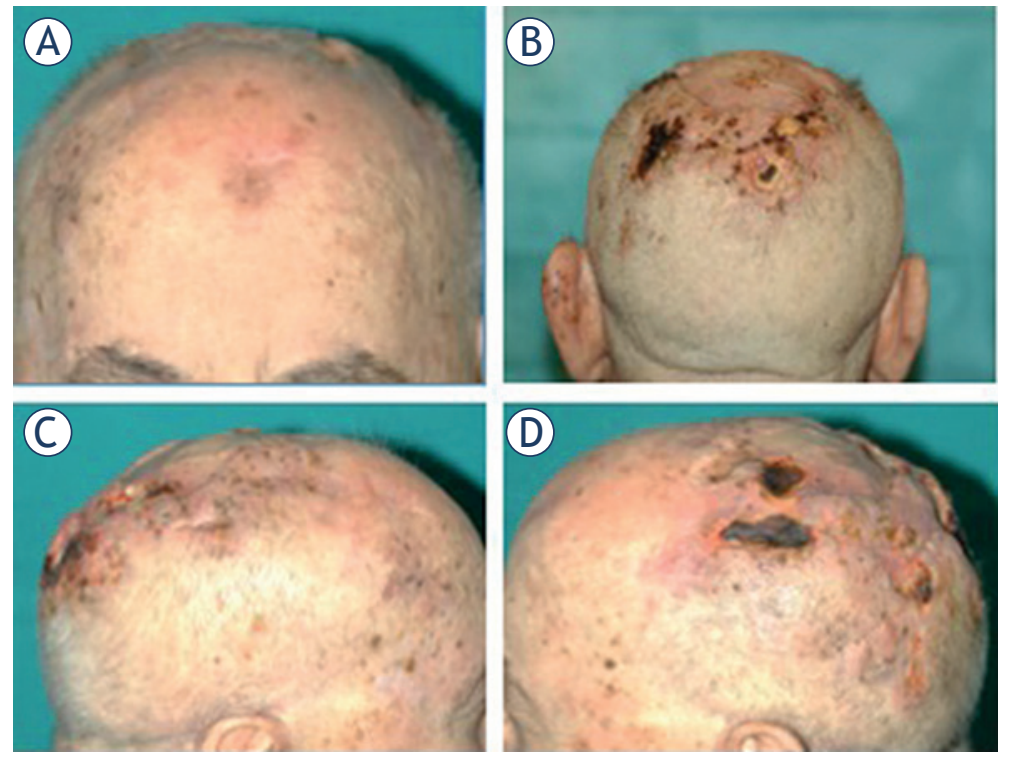

FIGURE 2. Response to treatment after two electrochemotherapy sessions (2 months).

\section{Electrochemotherapy for sebaceous carcinoma}

Herein we report a case of a 85-years old Caucasian male came to our attention for the first time presenting 9 papulo-nodular lesions on the scalp ranging from 1 to $3 \mathrm{~cm}$ in diameter (Figure $1 \mathrm{~A}-\mathrm{B}$ ). Moreover, some of them bled frequently. The clinical scenario was suggestive for locally metastatic cutaneous carcinoma but the eruptive emergence of skin lesions necessitated a better diagnostic determination. One year before, he had a prior surgical excision of a nodular lesion of the scalp carried out in another hospital treated with skin grafting and histologically diagnosed as cutaneous carcinoma.

Thus, we performed three skin biopsies on three different lesions with histopathological diagnosis of SC. The total body PET-CT scan confirmed the lack of visceral metastatic spreading.

A month after the first visit we observed the appearance of new lesions on the scalp and those previously described were increased in size. After collecting the informed consent for the off label procedure, we performed electrochemotherapy with a $30 \%$ reduced dose of the $15000 \mathrm{IU} / \mathrm{m}^{2}$ intravenous bleomycin due to the patient impaired renal function using the Cliniporator TM device (IGEA Ltd, Carpi, Italy). The treatment of tumour area of $20 \mathrm{~cm}^{2}$ was performed with hexagonal electrodes in 80 runs of electric pulse applications.

Neither post-treatment complications, nor cranial nerves injuries nor post-procedural pain were observed. Globally 16 lesions were treated with a complete bleeding control.

After one month the lesions treated were flat (Figure 1). Despite this other 4 new lesions appeared in the area on the previous skin graft. A second section of ECT was performed with the same parameters.

Two months after the second electrochemotherapy session the patients has not showed any relapse and was disease free (Figure 2).

\section{Discussion}

Herein we described the first case of Electrochemotherapy in the treatment of metastatic extraorbital SC. SC typically consists of roundish nests of tumour-cells with central necrosis, in proximity to normal sebaceous glands. The tumour cells of not well-differentiated SC may display high- grade features with a high frequency of mitotic figures. Angiolymphatic invasion is a consistent finding in SC, like an intraepidermal pagetoid tumour-spread.

The role of Immunohistochemistry in the diagnosis of SC is fundamental as it consistently expresses Epithelial Membrane Antigen (EMA) (which is absent in squamous cell carcinoma and basal cell carcinoma) and, in the centres of the tumour-nests, CD15. Surrounding sebaceous glands are used as a positive internal control for CD15. CD 10 is usually absent in SC. Ansai et al..$^{22}$ showed that positivity for adipophilin is most useful in the diagnosis of sebaceous neoplasms.

Because of the rarity of this tumour, no standard therapy exists specially in its metastatic onset. In the last years, electrochemotherapy has been proposed as a novel therapeutic option for the control of recurrent cutaneous, subcutaneous or mucosal neoplastic lesions of different histologies. ${ }^{23-24}$ There is an increasing body of published clinical data on electrochemotherapy. ${ }^{25}$ This procedure achieves rates of objective response between the $56 \%$ and the $100 \%$, depending on the tumour size and histology. ${ }^{26-27}$ Electrochemotherapy combines the administration of a poorly permeant cytotoxic agent, such as bleomycin with the local application of electric pulses that induce reversible electroporation, thus improving drug diffusion into cells. ${ }^{28}$ Electrochemotherapy has demonstrated a high rate of efficacy and favorable toxicity profile in a European multicenter study on skin metastases from different tumour histotypes. ${ }^{29}$ In this study, the objective response (OR) rate on treated tumour 
nodules was $89.0 \%$ with complete regression in $73.3 \%$ of cases. A recently published meta-analysis including 47 prospective studies comparing five skin-directed therapies (electrochemotherapy, radiation, photodynamic therapy, intralesional therapy, and topical therapy), electrochemotherapy demonstrated an OR rate of $75.4 \%$ (complete response [CR] rate $47.5 \%$ ) with a low toxicity profile (grade 3 in less than $6 \%$ of patients). ${ }^{30}$ The main advantages of electrochemotherapy include:

- high success rate in local tumour control after a single session;

- no damage to healthy peripheral tissue (using low doses of chemotherapeutic agents electrochemotherapy is very specific for dividing tumour cells, sparing the surrounding normal tissue);

- no protein denaturation, so that tumour antigens are not destroyed and may elicit an immune response;

- excellent safety profile (in clinical use, no serious adverse events were reported in association with electrochemotherapy;

- advantageous cost/benefit ratio: the technology and the drugs used, in particular bleomycin, do not require large investments;

- improvement of patient's quality of life.

Reported studies showed clinical activity, positive impact on patients subjective clinical perception and low toxicity profile of electrochemotherapy and encourages us to propose to patients this technique with an palliative intent, after the failure of conventional treatment options, such as surgery, radiotherapy, and systemic therapies. ${ }^{31}$ Especially in Kaposi Sarcoma, where skin lesions often cause pain and disfigurement and may lead to functional disability, electrochemotherapy has become the standard of care as first line treatment strategy. ${ }^{32}$

To the best of our knowledge no data on skin metastases from extracutaneous SC treated with electrochemotherapy are documented in the literature. Extraorbital SC has a high risk of local recurrence and it usually appears in elderly. Herein, we reported a CR at 2 months time from two sessions of electrochemotherapy for SC skin metastases. The choice of using electrochemotherapy in our patient was determined by the locally advanced pathology that would not permit a surgical resection and by the patient's refusal of radiotherapy. This case demonstrates that electrochemotherapy can be considered as an effective palliative treatment op- tion for patients with recurrent or advanced-stage tumour, not suitable for conventional treatments.

\section{References}

1. Warren S, Warvi WN. Tumors of sebaceous glands. Am J Pathol 1943; 19: 441-59.

2. Nelson BR, Hamlet KR, Gillard M, Railan D, Johnson TM. Sebaceous carcinoma. J Am Acad Dermatol 1995; 33: 1-15.

3. Tryggvason G, Bayon R, Pagedar NA. Epidemiology of sebaceous carcinoma of the head and neck: implications for lymph node management. Head Neck 2012; 34: 1765-8.

4. Samarasinghe V, Marsden J, Roberts C. Sebaceous carcinoma of the scalp presenting with nodal metastasis. J Plast Reconstr Aesthet Surg 2010; 63: 2193-4.

5. Buitrago W, Joseph AK. Sebaceous carcinoma: the great masquerader: emerging concepts in diagnosis and treatment. Dermatol Ther 2008; 21: 459-66.

6. Erovic BM, Goldstein DP, Kim D, Al Habeeb, Waldron J, Ghazarian D, A, et al. Sebaceous gland carcinoma of the head and neck: the Princess Margaret Hospital experience. Head Neck 2013; 35: 316-20.

7. Ansai S, Takeichi H, Arase S, Kawana S, Kimura T. Sebaceous carcinoma: an immuno-histochemical reappraisal. Am J Dermatopathol 2011; 33: 579-87.

8. Rumelt S, Hogan NR, Rubin PA, Jakobiec FA. Four-eyelid sebaceous cell carcinoma fol-lowing irradiation. Arch Ophthalmol 1998; 116: 1670-2.

9. Landis MN, Davis CL, Bellus GA, Wolverton SE. Immunosuppression and sebaceous tu-mors: a confirmed diagnosis of Muir-Torre syndrome unmasked by immunosuppressive therapy. J Am Acad Dermatol 2011; 65: 1054-8.

10. Shields JA, Demirci H, Marr BP, Eagle RC Jr, Shields CL. Sebaceous carcinoma of the eyelids: personal experience with 60 cases. Ophthalmology 2004; 111: 2151-7.

11. Dasgupta T, Wilson LD, Yu JB. A retrospective review of 1349 cases of sebaceous carcinoma. Cancer 2009; 115: 158-65.

12. Wang LS, Handorf EA, Wu H, Liu JC, Perlis CS, Galloway TJ. Surgery and adjuvant radiation for high-risk skin adnexal carcinoma of the head and neck. Am J Clin Oncol 2015; [Epub ahead of print]; PMID: 25599317

13. Ribero S, Osella-Abate S, Di Capua C, Dika E, Balagna E, Senetta R, et al. Squamocellu-lar carcinoma of the skin: clinicopathological features predicting the involvement of the surgical margins and review of the literature. Dermatology 2016; [Epub ahead of print]; PMID: 27028227

14. Mellette JR, Amonette RA, Gardner JH, Chesney TM. Carcinoma of sebaceous glands on the head and neck. A report of four cases. J Dermatol Surg Oncol 1981; 7: 404-7.

15. Bolm I, Babaryka G, Moergel M, Al-Nawas B, Kämmerer PW. Multifocal metastasizing extra-ocular facial sebaceous carcinoma as diagnostic challenge: case report and systematic review. J Maxillofac Oral Surg 2015; 14(Suppl 1): 331-7.

16. Moreno C, Jacyk WK, Judd MJ, Requena L. Highly aggressive extraocular sebaceous carcinoma. Am J Dermatopathol 2001; 23: 450-5.

17. Moura C, Pecegueiro MM, Sachse MF, Amaro J, Fonseca I, Fernandes A, et al. Report of a case of Muir-Torre syndrome. J Eur Acad Dermatol Venereol 2002; 16: 638-40.

18. Khan Z, Misra G, Fiander AN, Dallimore NS. Sebaceous carcinoma of the vulva. BJOG 2003; 110: 227-8.

19. Murphy J, Bleach NR, Thyveetil M. Sebaceous carcinoma of the nose: multifocal presentation? J Laryngol Otol 2004; 118: 374-6.

20. Swick JM, Lang PG Jr. Sebaceous gland carcinoma of the right flank. South Med J 2009; 102: 312-4.

21. Bhat IP, Madhukara J, Elizabeth J, Kini U, Anuradha A. Multifocal extra-ocular sebaceous carcinoma. Indian J Dermatol Venereol Leprol 2011; 77: 403.

22. Ansai S, Takeichi H, Arase S, Kawana S, Kimura T. Sebaceous carcinoma: an immuno-histochemical reappraisal. Am J Dermatopathol 2011; 33: 579-87. 
23. Macripò G, Caliendo V, Grassi M, Lista P, Ribero S, Giacone E, et al. Squamous cell car-cinoma of the umbilicus: management of an unusual localization. Tumori 2011; 97: 236-8.

24. Rotunno R, Marenco F, Ribero S, Calvieri S, Amerio P, Curatolo P, et al. Electrochemotherapy in non-melanoma head and neck skin cancers: a three centers experience and literature review. $G$ Ital Dermatol Venereol 2015; [Epub ahead of print]; PMID: 26376042

25. Campana LG, Clover AJ, Valpione S, Quaglino P, Gehl J, Kunte C, et al. Recommendations for improving the quality of reporting clinical electrochemotherapy studies based on qualitative systematic review. Radiol Oncol 2016; 50: 1-13.

26. Gargiulo M, Moio M, Monda G, Parascandolo S, Cubicotti G. Electrochemotherapy: actual considerations and clinical experience in head and neck cancers. Ann Surg 2010; 251: 773.

27. Mali B, Miklavcic D, Campana LG, Cemazar M, Sersa G, Snoj M, et al. Tumor size and effectiveness of electrochemotherapy. Radiol Oncol 2013; 47: 32

28. Mir LM, Orlowski S. Mechanisms of electrochemotherapy. Adv Drug Deliv Rev 1999; 35: 107-18.

29. Marty M, Sersa G, Garbay JR, Gehl J, Collins CG, Snoj M, et al. Electrochemotherapy -an easy, highly effective and safe treatment of cutaneous and subcutaneous metastases: results of ESOPE (European Standard Operating Procedures of Electrochemotherapy) study. Eur J Cancer 2006; 4(Suppl 11): 3-13.

30. Spratt DE, Gordon Spratt EA, Wu S, DeRosa A, Lee NY, Lacouture ME, et al. Efficacy of skin-directed therapy for cutaneous metastases from advanced cancer: a meta-analysis. J Clin Ocol 2014; 32: 3144-55.

31. Solari N, Spagnolo F, Ponte E, Quaglia A, Lillini R, Battista $M$, et al. Electrochemotherapy for the management of cutaneous and subcutaneous metastasis: a series of 39 patients treated with palliative intent. J Surg Oncol 2014; 109: 270-4.

32. Di Monta G, Caracò C, Benedetto L, La Padula S, Marone U, Tornesello ML, et al. Electrochemotherapy as "new standard of ca-re" treatment for cutaneous Kaposi's sarcoma. Eur J Surg Oncol 2014; 40: 61-6. 